\title{
The value of ultrasound in detecting pneumothorax
}

\author{
Andrew Verniquet, MD • Rafid Kakel, MD
}

Received: 23 August 2010/Accepted: 22 September 2010/Published online: 20 October 2010

(C) Canadian Anesthesiologists' Society 2010

\section{To the Editor,}

We read with interest the recent article, Ultrasound guidance for internal jugular vein cannulation, by Drs. Ayoub et al. ${ }^{1}$ that appeared in the May 2010 issue of the Journal. There are a number of points that we believe deserve emphasizing, for example, an absent sliding lung sign, although highly suggestive, is not diagnostic of a pneumothorax. ${ }^{2,3}$ When associated with A-lines, it should trigger a search for the lung point sign, ${ }^{3}$ which, if present, confirms an incomplete pneumothorax.

The absence of a lung point sign requires other diagnostic modalities to confirm a diagnosis. ${ }^{3}$ Other causes of absent sliding lung (e.g., acute respiratory distress syndrome, severe pneumonia, apnea, complete atelectasis, endobronchial intubation, pleural adhesions, high frequency ventilation) and the low prevalence of pneumothorax contribute to its lack of diagnostic certainty. From a purely statistical point, using a prevalence of $0.2 \%$ and a positive likelihood ratio of $121^{5}$ translate into a post-test probability of about $20 \%$ for a pneumothorax.

Sudden loss of B-lines or a sliding lung (as opposed to their absence) have been reported in cases of pneumothorax, although the evidence for these occurrences comes from case reports and small case series. ${ }^{6}$ This incident, however, makes a pre-procedural chest scan an attractive proposition. A pneumothorax may be ruled out in the horizontal supine patient by the presence of anterior lung sliding. In the absence of a sliding lung, a complete pneumothorax may be ruled out by the presence of B-lines. ${ }^{7}$

A. Verniquet, MD $(\square) \cdot R$. Kakel, MD

James Paton Memorial Hospital, Gander, NF, Canada

e-mail: andrewverniquet@hotmail.com
This article has no financial or non-financial affiliation and was not funded by any source.

Competing interests None declared.

\section{References}

1. Ayoub C, Lavallee C, Denault A. Ultrasound guidance for internal jugular vein cannulation: Continuing Professional Development. Can J Anesth 2010; 57: 500-14.

2. Lichtenstein D, Мепи $Y$. A bedside ultrasound sign ruling out pneumothorax in the critically ill. Lung sliding. Chest 1995; 108: 1345-8.

3. Lichtenstein DA, Meziere G, Lascols $N$, et al. Ultrasound diagnosis of occult pneumothorax. Crit Care Med 2005; 33: 1231-8.

4. McGee DC, Gould MK. Preventing complications of central venous catheterization. N Engl J Med 2003; 348: 1123-33.

5. Blaivas $M$, Lyon $M$, Duggal $S$. A prospective comparison of supine chest radiography and bedside ultrasound for the diagnosis of traumatic pneumothorax. Acad Emerg Med 2005; 12: 844-9.

6. Sartori S, Tombesi P, Trevisani L, Nielsen I, Tassinari D, Abbasciano $V$. Accuracy of transthoracic sonography in the detection of pneumothorax after sonographically guided lung biopsy: prospective comparison with chest radiography. AJR Am J Roentgenol 2007; 188: 37-41.

7. Lichtenstein D, Meziere G, Biderman P, Gepner A. The comet-tail artifact: an ultrasound sign ruling out pneumothorax. Intensive Care Med 1999; 25: 383-8.

\section{Reply}

We totally agree with the comment of Drs Verniquet and Kakel that the absence of a sliding lung is compatible but not necessarily diagnostic of a pneumothorax. In the article, we mentioned that the absence of a sliding lung sign "has been proven effective in detecting the presence of a pneumothorax". This phenomenon would be particularly useful if the sliding lung were present before the procedure 
and then absent after vascular access was performed. The major utility of the sliding lung is its negative predictive value, which approaches $100 \%$ in some studies. Therefore, if a sliding lung is present, pneumothorax can be almost ruled out. The presence of B-lines (comet-tail artifacts) or a lung pulse (cardiac transmission on the pleura) can also be used to rule out a pneumothorax. Consequently, their disappearance could also suggest this diagnosis. When performing echo-guided vascular access, the key element or message is that ultrasound can also be used to obtain critical information that is highly relevant to anesthesiologists. Lung ultrasonography is an area of significant interest for anesthesiologists, and we do share this point with Drs Verniquet and Kakel.

Funding This article has no financial or non-financial affiliation and was not funded by any source.

Competing interests None declared.

Christian Ayoub, MD

André Denault, MD

University of Montreal, Montreal, Canada 